\title{
Demonstration of vertebral and disc mechanical torsion in adolescent idiopathic scoliosis using three-dimensional magnetic resonance imaging
}

\author{
Daniel Birchall*, David Hughes and Brad Williamson
}

\author{
Address: Consultant and Head of Division, Northern Neurosciences Centre, Newcastle, UK \\ Email: Daniel Birchall* - Daniel.Birchall@nuth.nhs.uk \\ * Corresponding author
}

\author{
from 4th International Conference on Conservative Management of Spinal Deformities \\ Boston, MA, USA. 13-16 May 2007 \\ Published: 12 October 2007 \\ Scoliosis 2007, 2(Supp| I):S27 doi:I0.I|86/I748-7|6I-2-SI-S27
}

This abstract is available from: http://www.scoliosisjournal.com/content/2/SI/S27

(C) 2007 Birchall et al; licensee BioMed Central Ltd.

\section{Objectives}

To demonstrate and measure mechanical torsion in patients with adolescent idiopathic scoliosis using threedimensional magnetic resonance (MR) imaging.

\section{Methods}

Ten patients with adolescent idiopathic scoliosis were imaged with three-dimensional MR imaging, and the data post-processed through multiplanar reconstruction to produce images angled through individual endplates. Transverse rotation was measured at each endplate and these measurements used to calculate the amount of vertebral and disc mechanical torsion present. A test object was imaged in order to validate the measurement technique.

\section{Results}

Mechanical torsion was demonstrated within the vertebral bodies and discs of the imaged subjects, with vertebral mechanical torsion contributing on average forty-five percent of the overall transverse plane deformity.

\section{Conclusion}

Deformation occurs in the transverse plane within the vertebrae and discs of subjects with idiopathic scoliosis, and a significant proportion of the rotation present in the scoliotic spine occurs as a result of plastic deformation within the vertebrae themselves. We believe that this is the first systematic demonstration of mechanical torsion in idiopathic scoliosis. 